\title{
The 2014 geomagnetic jerk as observed by southern African magnetic observatories
}

\author{
P. B. Kotzé* (1)
}

\begin{abstract}
Rapid secular variation pulses in the Earth's geomagnetic field have been identified during the last decade. In particular, the 2014 jerk is the latest in a series of localised rapid secular variation events observed at the Earth's surface which are thought to be the result of rapid oscillations at the core surface approximately at a depth of $3000 \mathrm{~km}$. In Southern Africa, the 2014 jerk has been analysed using data from four observatories located at Hermanus, Hartebeesthoek, Keetmanshoop and Tsumeb and found that this event occurred with varying strengths in the different components at a particular observatory, while different observatories in the region showed strong individual characteristics. The changes in the secular variation patterns at individual magnetic observatories in this study took place in an area characterised by rapid changes in the geomagnetic field with time. Of particular interest is that global field models like CHAOS-6 and POMME 10 derived from various combinations of ground and satellite data do not always indicate similar short-period patterns in $X, Y$ and $Z$ as revealed by observatory measurements. This has been confirmed by comparing the secular variation pattern at the Kourou magnetic observatory located in French Guiana, a station close to the current centre of the South Atlantic Anomaly.
\end{abstract}

Keywords: Geomagnetism, Secular variation, Geomagnetic jerks

\section{Background}

Since the identification of the first geomagnetic jerk in 1969 by Courtillot et al. (1978) and Malin et al. (1983), several events related to rapid changes in the secular variation (SV) pattern of the Earth's magnetic field have been identified (see e.g. Mandea et al. 2010; Pinheiro et al. 2011; Brown et al. 2013). Secular acceleration (SA) pulses in the Earth's geomagnetic field during the last decade have been identified by Chulliat et al. (2010) using primarily data from the CHAMP satellite and magnetic observatories. In Southern Africa, the 2007 jerk as observed at the Hermanus magnetic observatory (Kotzé 2010, 2011) has been documented, while the 2012 jerk (Chulliat et al. 2015) shows a completely different morphology across Southern Africa (Kotzé and Korte 2016). An interesting feature of the most recent events in 2007 (Olsen et al. 2009; Chulliat et al. 2010) and 2012 (Chulliat and Maus 2014; Finlay et al. 2015) is that they appear

*Correspondence: pkotze@sansa.org.za

South African National Space Agency (SANSA), Space Science, Hermanus, South Africa to have their origin from a succession of core field acceleration pulses occurring predominantly in West Africa and the South Atlantic region. The 2014 jerk was first reported by Torta et al. (2015) showing evidence of strong secular acceleration in the Africa-South Atlantic region extending into Europe. Subsequently, Brown et al. (2016) confirmed the presence of widespread jerks across the globe between 2013 and early 2015, including areas such as Alaska using more recent geomagnetic field and SWARM satellite data.

An inspection of the appearance rate of geomagnetic jerks over the last decade showed that they occur at intervals ranging from 3 to 5 years, suggesting an oscillatory driving force within the core of the Earth. As the changes in the geomagnetic field are not uniformly spread across the globe (Bullard 1948), regions exist where the field changes are more rapid than elsewhere, like Southern Africa (Kotzé 2003; Mandea et al. 2007) and the South Atlantic ocean. Rapidly drifting core spots moving westwards towards South America have been ascribed by Bloxham and Gubbins (1985) to explain the observed high SV in Southern Africa. In this publication, 
it will be shown how the secular variation patterns of the different $X, Y$ and $Z$ field components differ at each observatory throughout the region of investigation. Of particular interest is the variation in strength of the 2014 geomagnetic jerk as revealed by the different field components. Both CHAOS-6 and POMME 10 (http:// www.geomag.org/models/pomme10.html) models were also compared to measurements made at the Kourou (KOU) magnetic observatory located in French Guiana (latitude $=5.21^{\circ}$, longitude $=307.3^{\circ}$, elevation $=10 \mathrm{~m}$ ) well inside the South Atlantic region and confirmed, like in Southern Africa, that SV observations are not always reproduced by model predictions, particularly around the 2014 geomagnetic jerk interval. The presence of unpredictable SV variations can have a negative impact on a global geomagnetic spherical harmonic field model such as IGRF-12 (Thébault et al. 2015) which is only updated every 5 years and having a linear prediction model over its lifetime.

The CHAOS-6 model (Finlay et al. 2016) is a geomagnetic field model based on satellite observations (Ørsted, CHAMP, SAC-C and SWARM A, B and C) as well as observatory monthly mean data between January 1997 and December 2015. Quasi-definitive data (Peltier and Chulliat 2010) until the end of 2015 were also utilised to determine secular variation values when definitive data were not available. The internal part of CHAOS- 6 is time-dependent up to degree and order 20 and involves sixth-order splines with a 0.5 -year knot spacing to provide secular variation information between 1997 and 2016 as well as secular variation predictions till 2020.

On the other hand, the POMME 10 main field model is based exclusively on CHAMP satellite vector magnetic measurements from July 2000 up to September 2010, Oersted satellite total field measurements from January 2010 to June 2014 and Swarm satellite vector magnetic measurements from December 2013 to November 2015. The time variations of the internal field are given by a piecewise linear representation of the Gaussian spherical harmonic coefficients of the magnetic potential.

These two global field models were used for cross-validation with our ground-based observatory secular variation data.

\section{Geomagnetic field observations and data}

Quiet-time data from continuous recordings of geomagnetic field variations conducted at the INTERMAGNET (www.intermagnet.org) geomagnetic observatories located at Hermanus (HER), Hartebeesthoek (HBK), Tsumeb (TSU) and Keetmanshoop (KMH) in Southern Africa (Kotzé et al. 2015) have been utilised to compile monthly mean values for the purpose of this investigation. A map showing the location of these four observatories is shown in Fig. 1 together with a scale to estimate the distances between the respective stations.

Quiet-time data were selected complying with the Dst ring current index required not to change by more than $3 \mathrm{nT} / \mathrm{h}$ and $\mathrm{K}$-indices less than or equal to 2 in order to eliminate disturbed and active geomagnetic conditions as far as possible. This selection restriction provided the best compromise between truly quiet times and the amount of data left to derive monthly values based on hourly means. These hourly data values were further corrected for ionospheric (plus induced) fields as well as large-scale magnetospheric (plus induced) fields using the CM4 comprehensive field model (Sabaka et al. 2004). Both arithmetic mean and median monthly values were obtained, but in most cases the differences between the two approaches were negligibly small. Data uncertainty estimates for observatory measurements depend entirely on the accuracy of baselines which at HER are approximately $50 \%$ more accurate compared to a remote location such as TSU or KMH where less frequent observations are made. Error estimates for observatory values for $X, Y$ and $Z$ components vary from $1 \mathrm{nT}$ at HER to $1.5 \mathrm{nT}$ for a remote location such as TSU or KMH. It is, however, not possible to assess how much external field influence still remains after all efforts have been made to reduce these signals in any observatory monthly mean or particular quiet-time value, and it is therefore expected that a small amount of external field leakage will still take place. To determine secular variation as free as possible from annual and seasonal variations resulting from magnetospheric and ionospheric currents, including the resulting induction effects, first differences of the $X, Y$ and $Z$ monthly means at time $t$ were calculated as the difference between those at time $t+6$ months and $t-6$ months. This has the implication that SV information is limited to 6 months before the last available main field observations. Therefore, data for the period from 2005.5 till 2015.5 were used to derive secular variation results for 2006-2015.

As KOU observatory was only considered for comparative purposes to evaluate the SV performance of the CHAOS-6 and POMME 10 field models in the South Atlantic region, mean monthly values were obtained from the World Monthly Means Project (Chulliat and Telali 2007) database (ftp.bcmt.fr) in Paris, with quasidefinitive values extending well into 2016 .

\section{Secular variation behaviour around 2014}

In order to characterise the times of the rapid secular variation changes and compare how well the CHAOS-6 and POMME 10 models describe the secular variation in Southern Africa, the different $X-, Y$ - and $Z$-component time series were investigated at the four 


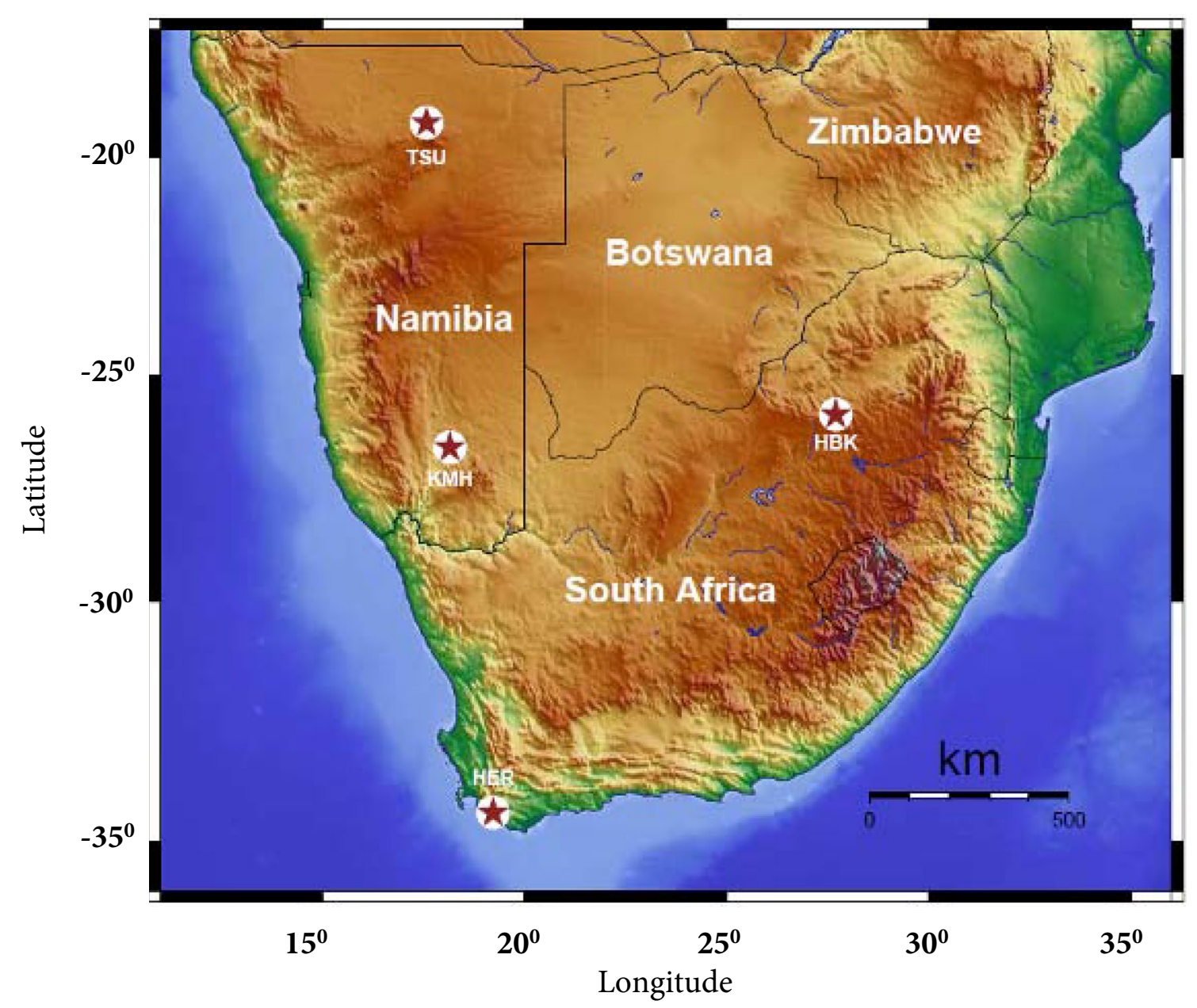

Fig. 1 A map of Southern Africa showing the positions (red stars) of the four INTERMAGNET observatories HER, HBK, KMH and TSU

individual observatory locations at HER, HBK, KMH and TSU. Results for $X, Y$ and $Z$ are shown in Figs. 2, 3 and 4, respectively, as a function of time between 2006 and 2015 as determined by running annual differences of the quiettime monthly mean values. Predictions of secular variation from both the global CHAOS-6 and POMME 10 models are included in these plots. In a previous investigation (Kotzé and Korte 2016), the focus was on the secular variation of the $D, H$ and $Z$ components at HER, HBK, KMH and TSU in the time period 2005-2014. In this investigation, the focus is placed exclusively on the secular variation behaviour of $X, Y$ and $Z$ components around 2014 in Southern Africa, a region where rapid changes in the geomagnetic field are taking place at the moment.

Additionally, rates of SV change were estimated directly from the time series by piecewise linear fits, which are also shown in the different figures. To determine the break points between two linear segments, an algorithm searched for a distinctive change in the slope of consecutive segments. An iterative method was then applied to obtain the best linear fit and subsequently the slope of a particular time interval by optimising the regression coefficient.

The $X$ component of the geomagnetic field is normally most likely to be influenced by external field effects, particularly the ring current. The stringent data selection and processing procedure applied in this study did reduce the scatter in the $X$ time series at all observatories. However, from Fig. 1 it is obvious that a certain amount of scatter due to leakage of external fields is still present, but it had no influence on the morphology of the secular variation behaviour. The behaviour of the $X$-component $S V$ at HER around 2014, the most southern observatory in the area under investigation, is similar to what is observed at the other observatories HBK and KMH, while at TSU no detectable change in the time variation pattern could be observed. Between 2013 and 2015, the $X$-component secular variation decreases at a rate of $-10.5 \mathrm{nT} /$ year $^{2}$ and 


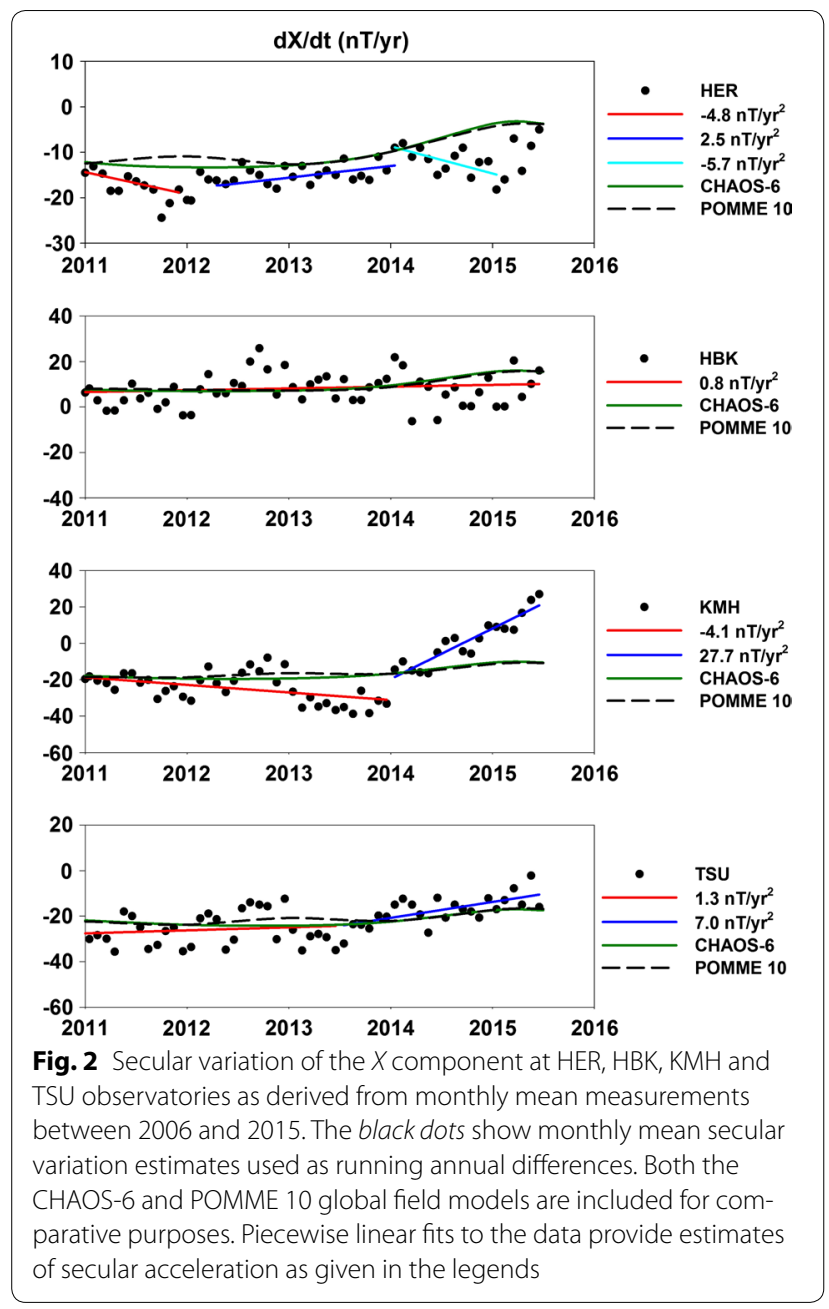

then increases at a rate of $7.3 \mathrm{nT} /$ year $^{2}$ after 2014, giving a strength of $17.82 \mathrm{nT} /$ year $^{2}$ for the SV change at HER around 2014. Although both the CHAOS-6 and POMME 10 models agree quite good with observations at HER between 2012 and 2014, both show a fair amount of disagreement for the period after 2014. The same tendency could also be observed at KOU (Fig. 5). In contrast to other observatories, TSU, the most northern observatory in this area, does not show any secular change in $X$ and is mostly constant at a rate of $1.6 \mathrm{nT} /$ year $^{2}$ between 2010 and 2015. This is confirmed by CHAOS -6 and POMME 10 . On the other hand, $\mathrm{KMH}$ exhibits a decrease in $X$-component secular variation between 2013 and 2014 at a rate of $-21.1 \mathrm{nT} / \mathrm{year}^{2}$, while after 2014 a rapid increase in the rate of change of $27.7 \mathrm{nT} /$ year $^{2}$ is observed, providing a jerk strength of 48.7 nT/year ${ }^{2}$. Both the CHAOS- 6 and POMME 10 models provide very good agreements with observations at KMH before 2014, but after 2014 we could observe substantial differences between model and SV observations. At TSU, a substantial amount of scatter in the $X$-component secular variation measurements could be observed, with both CHAOS-6 and POMME 10 in close agreement with TSU experimental data.

The $Y$-component secular variation at HER exhibits a diminishing tendency from around 2012, changing from -2.1 to $-6.8 \mathrm{nT} / \mathrm{year}^{2}$ around 2014. Both CHAOS-6 and POMME 10 did not show any change in SV around 2014 at HER. The $Y$-component SV at HBK shows a rapid change from approximately -1.0 to $-8.3 \mathrm{nT} /$ year $^{2}$ around 2014, while both CHAOS-6 and POMME 10 do not show any change in the SV pattern. In contrast to Hartebeesthoek $\left(25.88^{\circ} \mathrm{S}\right)$, Keetmanshoop $\left(26.54^{\circ} \mathrm{S}\right)$ which is located at approximately the same latitude but different longitude, the $Y$-component secular variation diminished at a rapid rate of $-20.7 \mathrm{nT} /$ year $^{2}$ between 2012 and 2013, while after this date it increases at a rate of $15.3 \mathrm{nT} /$ year $^{2}$. CHAOS-6, however, does not support any of these rapid variations observed at $\mathrm{KMH}$, while POMME10 does show an indication of a change in secular variation around 2014, although much smoother than the experimental data indicate. At KOU (Fig. 5) observatory on the other side of the Atlantic, several changes in the SV behaviour can be observed between 2006 and 2015. Both CHAOS-6 and POMME 10 describe the 2007 jerk very well, while the 2012 and 2014 events are also represented at various degrees of success by both models. TSU, at approximately the same longitude as $\mathrm{KMH}$ and HER, but located further north at a latitude of $19.22^{\circ} \mathrm{S}$, displays a $Y$-component secular variation that is approximately 6 months later than at $\mathrm{KMH}$. In the period before 2013, the $Y$-component SV increases at a rate of $2.2 \mathrm{nT} /$ year $^{2}$, only to decrease at a rate of $-26.4 \mathrm{nT} /$ year $^{2}$ till 2013.5 when it started to increase again at a rate of $4.2 \mathrm{nT} /$ year $^{2}$. CHAOS- 6 on the other hand does not agree with these observations at TSU and shows a constant rate of change, while POMME10 does indeed indicate a jerk behaviour around 2013, although of opposite strength to experimental observations.

An analysis of Fig. 4 reveals almost similar secular variation behaviour at both HER and HBK for the $Z$ component around 2014. In the case of HER, the SV increases at a rate of $3.3 \mathrm{nT} /$ year $^{2}$ from around 2012 till approximately 2013.5 , only to decrease a rapid rate of $-16.7 \mathrm{nT} /$ year $^{2}$ till 2014.0 before it starts to increase again at a rate of $8.1 \mathrm{nT} /$ year $^{2}$. The situation almost repeats itself at HBK, only that between 2012 and 2013.5 the $Y$-component secular variation increases at an estimated rate of $4.7 \mathrm{nT} / \mathrm{year}^{2}$, while between 2013.5 and 2014.5 we see a diminishing rate of $-29.7 \mathrm{nT} /$ year $^{2}$. From approximately 2014.5, the $\mathrm{SV}$ increases again at a rate of $12.5 \mathrm{nT} /$ year $^{2}$. CHAOS-6 provides a good prediction of SV in both cases up until 2014, but after 2014 this comparison deteriorates very rapidly. The POMME 10 model, however, does not agree 

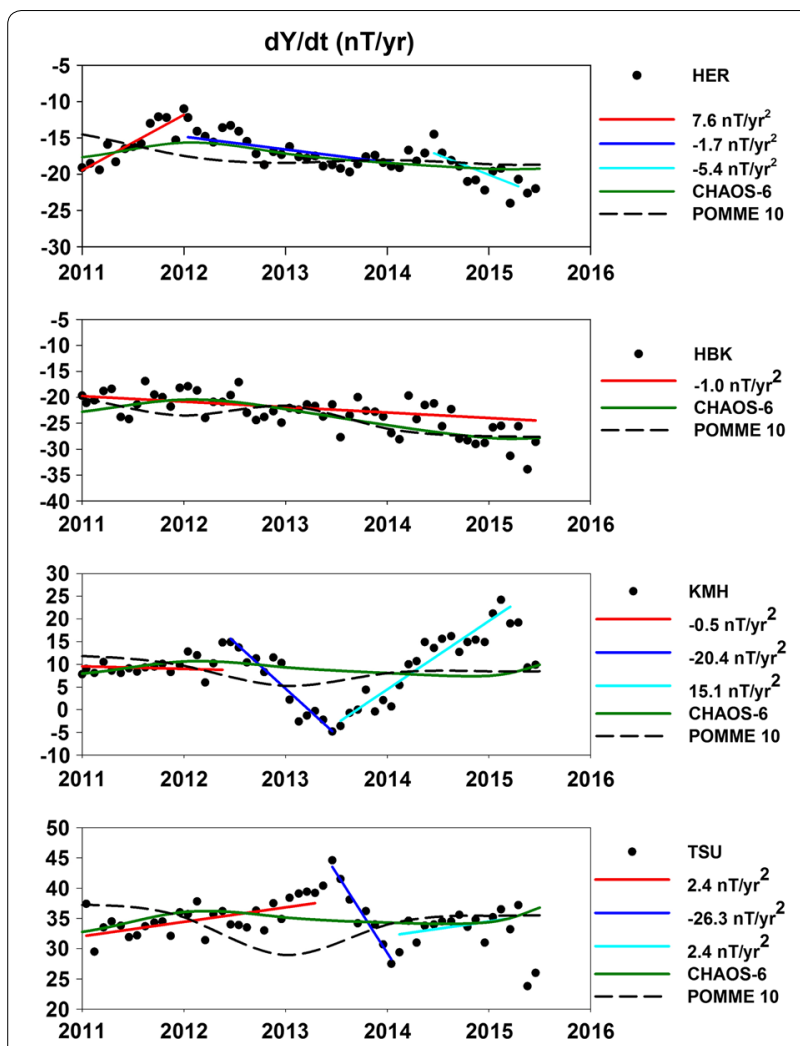

Fig. 3 Secular variation of the $Y$ component as measured between 200511 and 2015 at Southern African magnetic observatories HER, HBK, KMH and TSU. The black dots show monthly mean secular variation estimates derived as running annual differences. CHAOS-6 and POMME 10 model predictions are also included. Piecewise linear fits to the data provide estimates of secular acceleration as given in the different legends

very well with observations at $\mathrm{HER}$, while at $\mathrm{HBK}$ the agreement deteriorates after 2012, similar to CHAOS-6. In the case of both KMH and TSU observatories, $Z$-component secular variation declines between 2010 and 2013.5 at a rate of -3.2 and $-3.6 \mathrm{nT} / \mathrm{year}^{2}$, respectively, while from around 2013.5 the secular variation increases at a rate of 15.5 and $8.8 \mathrm{nT} /$ year $^{2}$, respectively. CHAOS-6 also seems to capture the change in slope at $\mathrm{KMH}$ around 2013.5 fairly well although the modelled values exhibit a more gradual pattern than evidenced by experimental data. The POMME 10 model on the other hand indicates a change in SV around 2013 at KMH very accurately. Both models seem to follow the same tendency at TSU, with excellent correlation with observations during the whole period 2006-2015. According to Fig. 5, the $Z$ component at KOU exhibits several secular variation changes during the period between 2006 and 2015. Both CHAOS-6 and POMME 10 seem to capture the 2007 jerk equally well, but for the 2014 event POMME 10 provides a more realistic representation of the observed behaviour.

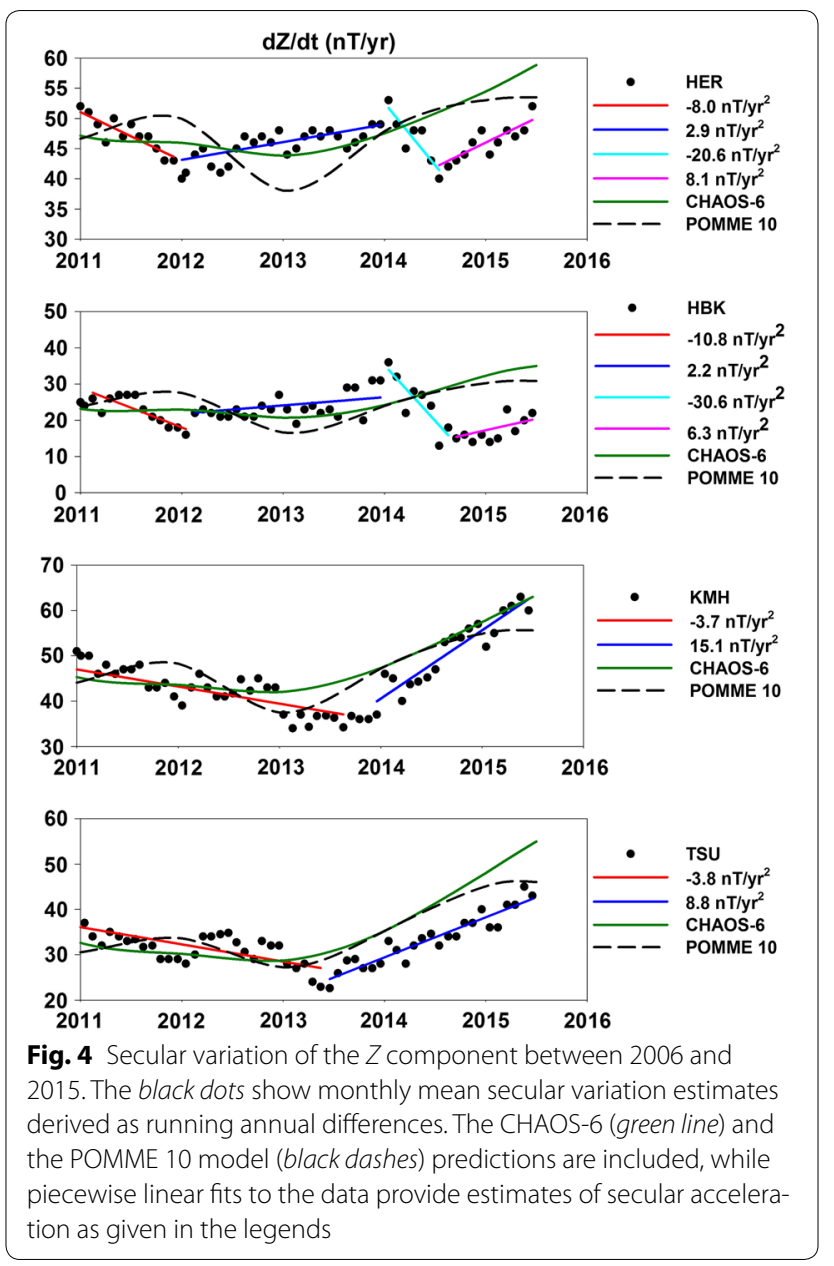

The strengths of rapid SV changes or jerks during 2013-2015 are listed in Table 1.

\section{Conclusions}

Using quiet-time monthly mean geomagnetic $X, Y$ and $Z$ data from four observatories, we investigated the occurrence as well as the strength of the 2014 geomagnetic jerk in Southern Africa, first reported by Torta et al. (2015). Evidence of the 2014 geomagnetic jerk could be found in all field components, but not at all observatories. In this regard, TSU was the exception with no evidence of any change in secular variation in the $X$ component. In the case of $X$, the jerk was positive at HER, HBK and KMH with the strongest amplitude $\left(48.7 \mathrm{nT} /\right.$ year $\left.^{2}\right)$ recorded at KMH taking place during the 2013-2014 interval. The jerk in $Y$ at both HER $\left(-4.7 \mathrm{nT} /\right.$ year $\left.^{2}\right)$ and HBK $(-7.4 \mathrm{nT} /$ year $^{2}$ ) was negative and took place around 2014.0, while in the case of $\mathrm{KMH}$ it was the strongest and positive (36.0 nT/year ${ }^{2}$ ), occurring earlier during 2013. An analysis of the behaviour of the Z-component SV pattern across Southern Africa also reveals interesting results. 


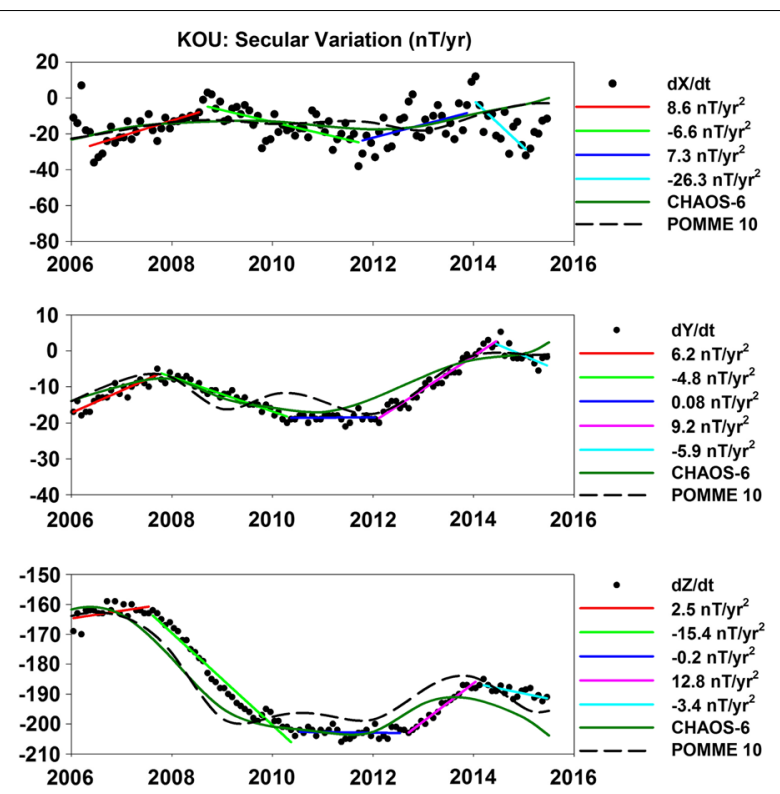

Fig. 5 Secular variation of $X, Y$ and $Z$ components at Kourou observatory as derived from monthly means between 2006 and 2016. The CHAOS-6 and POMME 10 global field models are shown for comparative purposes

Table 1 Amplitudes and signs of secular acceleration changes at the four observatories as determined from changes in slope of the piecewise linear fitting (Figs. 2, 3, 4)

\begin{tabular}{lllll}
\hline Interval & HER & HBK & KMH & TSU \\
\hline$X\left(\right.$ nT/year $\left.{ }^{2}\right)$ & & & & \\
$2013-2014$ & - & - & 48.7 & - \\
$2014-2015$ & 17.8 & 27.3 & & - \\
$Y\left(n T /\right.$ year $\left.{ }^{2}\right)$ & & & & 30.7 \\
$2013-2014$ & - & - & 36.0 & - \\
$2014-2015$ & -4.7 & -7.4 & - & 12.4 \\
$Z\left(n T /\right.$ year $\left.^{2}\right)$ & & & & - \\
$2013-2014$ & -20.0 & -34.4 & 18.7 & - \\
$2014-2015$ & 24.8 & 42.2 & & \\
\hline
\end{tabular}

At $\mathrm{KMH}$, the last identified geomagnetic jerk occurred during 2009-2010 with an amplitude of -18.6 nT/year ${ }^{2}$ (Kotzé and Korte 2016). The 2014 jerk event at KMH had a strength of $18.7 \mathrm{nT} /$ year $^{2}$, which is exactly the same as the 2009-2010 event, but of opposite polarity. This is in line with the findings by Brown et al. (2013) as well as Chulliat and Maus (2014) that the periodicity in the polarity of geomagnetic jerks does indeed oscillate on a regular basis between comparable maximum and minimum amplitudes. This could, however, not be confirmed at the other observatories in Southern Africa as we did not observe consecutive geomagnetic jerks of comparable strengths in this investigation.

Recent investigations of secular acceleration pulses in the Earth's magnetic field (e.g. Chulliat et al. 2010) have concluded that these rapid secular variation events observed at the Earth's surface are the result of rapid oscillations at the core-mantle boundary. This behaviour observed in Southern Africa can most probably be related to the oscillatory SV behaviour at the core surface underneath the Southern Atlantic region, resulting from either oscillations in the non-axisymmetric part of the east-west core flow at low latitudes (Gillet et al. 2015), or MHD effects at the top of the core surface (Chulliat et al. 2015). Information obtained in this investigation regarding the jerk around 2014 in Southern Africa supports findings by Torta et al. (2015) that jerks are not always observed simultaneously in all geomagnetic field components at a particular observatory (Mandea et al. 2010). Although great care has been taken to obtain quiet-time observatory magnetic field data, it is, however, possible that a small amount of external field influence can still be present. This is particularly true for the $X$ component which is most sensitive to ring current perturbations. A comparative evaluation of different quiet-time data selection procedures did not change the final results in this investigation, but did contribute to an improved correlation between model values and experimental observations.

It is also evident that both CHAOS-6 and POMME 10 are not able to always fit the geomagnetic secular variation changes in Southern Africa. This apparent shortcoming depends on both geographic position as well as the particular geomagnetic field component, as was shown in the comparison with the Kourou magnetic observatory located in French Guyana. Our previous investigation into the secular variation of $D, H$ and $Z$ in Southern Africa (Kotzé and Korte 2016) showed that the 2007 geomagnetic secular variation changes could be very well represented by the CHAOS series of global models. This was also true for the $Y$ and $Z$ components at KOU around 2007. In contrast to the 2007 results, the secular variation changes around 2014 and beyond could be less accurately represented by both CHAOS- 6 and POMME 10 global field models in several cases. This is likely due to the lack of accurate global data close to the model endpoints, forcing modellers to apply unrealistic endpoint conditions that can result in a deterioration of the quality of model secular variation descriptions close to the endpoints. One possibility to improve the current situation is that more observatories provide quasi-definitive data on a prompt and regular basis.

The findings in this paper can be regarded as a direct follow-up of a previous publication (Kotzé and Korte 
2016) on secular variation observations in Southern Africa for the period between 2005 and 2014.

Future investigations using both SWARM and observatory measurements have the potential to provide further insights to explain the origin and driving mechanism of rapid geomagnetic secular variation pulses.

\section{Acknowledgements}

The CHAOS-6 field model coefficients used in this investigation were downloaded from the website http://www.spacecenter.dk/files/magneticmodels, while the POMME 10 model coefficients were obtained at http://www. geomag.org/models/pomme10.html. PK was supported by an NRF Grant (no. 103610) for rated researchers. The support provided by the German Centre for Geosciences (GFZ) in Potsdam to run and maintain the Keetmanshoop magnetic observatory according to INTERMAGNET standards is appreciated.

\section{Competing interests}

The author declares that he has no competing interests.

Received: 1 September 2016 Accepted: 19 January 2017

Published online: 25 January 2017

\section{References}

Bloxham J, Gubbins D (1985) The secular variation of Earth's magnetic field. Nature 317:777-78

Brown WJ, Mound JE, Livermore PW (2013) Jerks abound: an analysis of geomagnetic observatory data between 1957 and 2008. Phys Earth Planet Inter 223:62-76. doi:10.1016/j.pepi.2013.06.001

Brown WJ, Beggan C, Macmillan S (2016) Geomagnetic jerks in the SWARM era. ESA Living Planet Symposium, EART-26, Solid Earth and Near Earth, \#1547

Bullard EC (1948) The secular change in the Earth's magnetic field. Mon Not R Astron Soc Geophys Suppl 5:248-257

Chulliat A, Maus S (2014) Geomagnetic secular acceleration, jerks, and a localized standing wave at the core surface from 2000 to 2010. J Geophys Res. doi:10.1002/2013JB010604

Chulliat A, Telali K (2007) World monthly means DataBase project. Publ. Inst. Geophys. Pol. Acad. Sc., C-99 (398)

Chulliat A, Thébault E, Hulot G (2010) Core field acceleration pulse as a common cause of the 2003 and 2007 geomagnetic jerks. Geophys Res Lett. doi:10.1029/2009GL042019

Chulliat A, Alken P, Maus S (2015) Fast equatorial waves propagating at the top of the Earth's core. Geophys Res Lett. doi:10.1002/2015GL064067
Courtillot V, Ducruix J, Le Mouel JL (1978) Sur une accélération récente de la variation séculaire du champ magnétique terrestre. C R Acad Sci Paris D 287:1095-1098

Finlay CC, Olsen N, Tøffner-Clausen L (2015) DTU candidate field models for IGRF-12 and the CHAOS-5 geomagnetic field model. Earth Planets Space 67:114. doi:10.1186/s40623-015-0274-3

Finlay CC et al (2016) Recent geomagnetic secular variation from Swarm and ground observatories as estimated in the CHAOS-6 geomagnetic field model. Earth Planets Space 68:112. doi:10.1186/s40623-016-0486-1

Gillet N, Jault D, Finlay CC (2015) Planetary gyre and time-dependent midlatitude eddies at the Earth's core surface. J Geophys Res. doi:10.1002/20 14JB011786

Kotzé PB (2003) The time-varying geomagnetic field of Southern Africa. Earth Planets Space 55:111-116

Kotzé PB (2010) The 2007 geomagnetic jerk as observed at the Hermanus Magnetic Observatory. Phys Comment 2:5-6

Kotzé PB (2011) Signature of the 2007 geomagnetic jerk at the Hermanus Magnetic Observatory, South Africa. S A J Geol 114(2):207-210. doi:10.2113/gssajg.114.2.207

Kotzé PB, Korte M (2016) Morphology of the southern African geomagnetic field derived from observatory and repeat station survey observations: 2005-2014. Earth Planets Space 68:23. doi:10.1186/s40623-016-0403-7

Kotzé PB, Cilliers PJ, Sutcliffe PR (2015) The role of SANSA's geomagnetic observation network in space weather: a review. Space Weather. doi:10.1 002/2015SW001279

Malin SRC, Hodder BM, Barraclough DR (1983) Geomagnetic secular variation: a jerk in 1970. In: Publicaciones del Observatorio del Ebro. Memoria, 14. pp 239-256

Mandea M, Korte M, Mozzoni D, Kotze P (2007) The magnetic field changing over the southern African continent-a unique behaviour. S A J Geol 110:193-202

Mandea M, Holme R, Pais A, Pinheiro K, Jackson A, Verbanac G (2010) Geomagnetic jerks: rapid core field variations and core dynamics. Space Sci Rev 155:147-175. doi:10.1007/s11214-010-9663-x

Olsen N, Mandea M, Sabaka TJ, Tøffner-Clausen L (2009) CHAOS-2-A geomagnetic field model derived from one decade of continuous satellite data. Geophys J Int 179:1477-1487. doi:10.1111/j.1365-246X.2009.04386.x

Peltier A, Chulliat A (2010) On the feasibility of promptly producing quasidefinitive magnetic observatory data. Earth Planets Space 62:e5-e8. doi:10.5047/eps.2010.02.002

Pinheiro KJ, Jackson A, Finlay CC (2011) Measurements and uncertainties of the occurrence time of the 1969, 1978, 1991, and 1999 geomagnetic jerks. Geochem Geophys Geosyst 12:Q10015. doi:10.1029/2011GC003706

Sabaka TJ, Olsen N, Purucker ME (2004) Extending comprehensive models of the Earth's magnetic field with Ørsted and CHAMP data. Geophys J Int 159:521-547

Thébault E et al (2015) Evaluation of candidate geomagnetic field models for IGRF-12. Earth Planets Space 67:1 10. doi:10.1186/s40623-015-0273-4

Torta JM, Pavón-Carrasco FJ, Marsal S, Finlay C (2015) Evidence for a new geomagnetic jerk in 2014. Geophys Res Lett. doi:10.1002/2015GL065501

\section{Submit your manuscript to a SpringerOpen ${ }^{\odot}$ journal and benefit from:}

- Convenient online submission

- Rigorous peer review

- Immediate publication on acceptance

- Open access: articles freely available online

- High visibility within the field

- Retaining the copyright to your article

Submit your next manuscript at $>$ springeropen.com 